\title{
Entre o pensar e o fazer: narrativas através das fotografias de quem vive a periferia ${ }^{1}$
}

\author{
Entre el pensar y hacer: narrativas a través de las fotografías de quien \\ vive la perifería
}

\author{
Between think and do: narrations through photographs of life on the \\ periphery
}

\author{
Pillar Alves Paladini
}

\begin{abstract}
Resumo
O presente trabalho visa apresentar a pesquisa de mestrado, em andamento, sobre narrativas das periferias. Utilizando a fotografia enquanto ferramenta de pesquisa e dispositivo para reflexão, ambiciona-se promover esta linguagem como meio de expressão e experimentação na comunicação social, tornando-a assim um instrumento social. Na perspectiva da Antropologia compartilhada, estudantes do Ensino Fundamental II, de escolas situadas em regiões periféricas da cidade do Rio de Janeiro, produzirão fotografias que trarão um olhar de quem vive estas fronteiras. A cidade, as imagens e a vida serão os temas que nutrirão a pesquisa, focando em territórios periféricos por compreender que se faz necessário deslocar o olhar do centro em direção às fronteiras, ao marginalizado. A fotografia é explorada aqui como possibilidade de um terreno fértil, laborativo, colaborativo e libertador, compreendendo o potencial único do visual enquanto forma de intervenção social e antropológica. A ideia é suscitar, através do uso de tecnologias DIY (Do It Yourself), questões que vão além da esfera biologicamente vital, isto é, do ir e vir cotidiano. A linguagem escolhida foi a fotografia por conter em si mesma a eficácia das formas visuais enquanto linguagem dialógica. Nos convida a considerar mais a sério o quanto o visual pode ser antropologicamente informado. É educar o olhar para atos que envolvem o observar, o refletir e o produzir, de modo que a transitividade da consciência perpasse a inserção, integração e representações diversas da realidade.
\end{abstract}

Palavras-Chave: educação; fotografia; jovens; narrativas; periferias

\section{Resumen}

El presente trabajo pretende presentar la investigación de maestría, en marcha, sobre narrativas de las periferias. Utilizando la fotografía como herramienta de investigación y dispositivo para reflexión, se ambiciona promover este lenguaje como medio de expresión y experimentación en la comunicación social, convirtiéndola así en un instrumento social. En la perspectiva de la Antropología compartida, estudiantes de la Enseñanza Fundamental II, de escuelas situadas en regiones periféricas de la ciudad de Río de Janeiro, producirán fotografías que traerán una mirada de quien vive estas fronteras. La ciudad, las imágenes y la vida serán los temas que nutrirán la investigación, enfocándose en territorios periféricos por comprender que se hace necesario desplazar la mirada del centro hacia las fronteras, al marginado. La fotografía es explorada aquí como posibilidad de un terreno fértil, laborativo, colaborativo y liberador, comprendiendo el potencial único del visual como forma de intervención social y antropológica. La idea es suscitar, a través del uso de tecnologías DIY (Do It Yourself), cuestiones que van más allá de la esfera biológicamente vital, es decir, del ir y venir cotidiano. El lenguaje escogido fue la fotografía por contener en sí misma la eficacia de las formas visuales como lenguaje dialógico.

\footnotetext{
${ }^{1}$ Artigo apresentado no Simpósio Temático Comunicação, narrativas audiovisuais e semiótica durante o II Seminário Latino-Americano de Estudos em Cultura - SEMLACult em Foz do Iguaçu/PR, Brasil, 2018

${ }^{2}$ Mestranda no Programa de Pós-graduação em Educação, Cultura e Comunicação em Periferias Urbanas; Faculdade de Educação da Baixada Fluminense (FEBF) da Universidade do Estado do Rio de Janeiro (UERJ); Rio de Janeiro/RJ, Brasil; pillarpaladini@ hotmail.com
} 
Nos invita a considerar más en serio lo visual que puede ser antropológicamente informado. Es educar la mirada hacia actos que involucran el observar, el reflejar y el producir, de modo que la transitividad de la conciencia pierda la inserción, integración y representaciones diversas de la realidad.

Palabras clave: educación; fotografía; joven; narrativas; periferias.

\begin{abstract}
The present work aims to present the master's research, in progress, about narratives of the peripheries. Using photography as a research tool and device for reflection, it aims to promote this language as a means of expression and experimentation in social communication, thus making it a social instrument. From the perspective of shared anthropology, elementary school students from schools located in outlying regions of the city of Rio de Janeiro will produce photographs that will bring a glimpse of those who live in these frontiers. The city, the images and the life will be the subjects that will nourish the research, focusing on peripheral territories for understanding that it is necessary to shift the gaze from the center towards the borders, to the marginalized. Photography is explored here as the possibility of a fertile, laborious, collaborative and liberating terrain, understanding the unique potential of the visual as a form of social and anthropological intervention. The idea is to elicit, through the use of DIY (Do It Yourself) technologies, issues that go beyond the biologically vital sphere, that is, the daily coming and going. The language chosen was photography because it contained in itself the efficacy of the visual forms as a dialogic language. It invites us to consider more seriously how visual can be anthropologically informed. It is to educate the look at acts that involve observing, reflecting and producing, so that the transitivity of consciousness goes through insertion, integration and diverse representations of reality.
\end{abstract}

Keywords: education; photography; narratives; peripheries; young

\title{
1. Introdução
}

A questão da identidade e das representações culturais estão sendo extensamente discutidas nos ambientes diversos, sejam estes midiáticos ou instituições formais como a escola, no plano individual ou coletivo. $\mathrm{O}$ indivíduo moderno encontra-se fragmentado, ao qual apenas uma referência ou adjetivo não comporta todas as subjetividades do qual ele é formado. Hall (2006, p. 11) trata das chamadas "identidades culturais", isto é, "aqueles aspectos de nossas identidades que surgem de nosso "pertencimento" a culturas étnicas, raciais, linguísticas, religiosas e, acima de tudo, nacionais."

Aspiro me debruçar para além dos muros da educação, da pesquisa focada tão somente nas paredes conteudistas da sala de aula tradicional. Deste modo, realizar um estudo que permita a união de três assuntos que despertam imensamente minha curiosidade epistemológica - educação, cultura e comunicação - apresenta-se como uma oportunidade ímpar no cenário de minha formação profissional e de contribuição para a área educacional.

Enquanto pedagoga que circunscreve um projeto de mestrado que trabalhará com a fotografia, coloco-me integralmente enquanto educadora que percebe na linguagem fotográfica uma possibilidade outra de educação, uma educação tanto libertadora quanto para a transgressão, bebendo em Freire e hooks. De todas as vezes que estava de costas para o quadro e de frente para a classe, pensava o que meus olhos viam, mas não detinham. Que histórias e narrativas fugiam à captura das minhas retinas que não enxergavam além do óbvio 
(ou do que a rotina sufocante não permitia me sensibilizar). Deste modo, ciente da suma importância da boa relação professor-aluno para uma trajetória tanto quanto mais positiva de construção do conhecimento, como ampliar essa visão apequenada - e quando não estigmatizada - dos sujeitos que, afinal, são o cerne da existência docente? Como captar o não dito, alargar e aprofundar as identidades destes sujeitos para além do nome e vivências trazidas no cotidiano?

\section{A fotografia enquanto possibilidade pedagógica}

Nas relações escolares, muitas vezes estabelecidas através de uma hierarquia baseada na verticalização de conhecimentos e desvalorização do educando, o acesso ao outro não é possível tendo em vista essa concepção de estrutura. Através da fotografia, os regimes discursivos podem sofrer uma reorganização, permitindo uma reestruturação deste ponto de vista hierarquizado.

Como explicita Paulo Freire, devem-se dar condições para que os educandos e docentes, em suas relações, ensaiem a experiência de assumir-se como ser social e histórico, pensante, transformador, realizador de sonhos. Para o autor, "a construção de nossa presença no mundo não se faz no isolamento, sem forças sociais. (...) A função ontológica (ciência do ser) é a de intervir no mundo; posição de quem luta para ser sujeito, e não apenas objeto." (FREIRE, 1997, p.22)

Sujeitos atuantes pressupõem o conceito de autonomia e emancipação e, apesar destas categorias serem abstratas, encontram-se em uma relação dialética entre o pensamento e a prática educacional. Para problematizar a indústria cultural e seus produtos devemos considerar que:

(...) em primeiro lugar, a própria organização do mundo em que vivemos e a ideologia dominante - hoje muito pouco parecida com uma determinada visão de mundo ou teoria ou seja, a organização do mundo converteu-se a si mesma imediatamente em sua própria ideologia. (...) De um certo modo, emancipação significa o mesmo que conscientização, racionalidade. Mas a realidade sempre é simultaneamente uma comprovação da realidade, e esta envolve continuamente um movimento de adaptação. (ADORNO, 1967)

Adorno usa o termo "well adjusted people" para designar pessoas bem ajustadas, uma das consequências de uma educação voltada para a mera adaptação. Em tempos onde captar a imagem e publicar torna-se quase substituível ao próprio ato de viver o momento, substituindo a experiência (NOVAES, 2009, p.40), refletir acerca das produções das imagens do cotidiano é uma possibilidade dos tempos modernos. Em um mundo onde as redes sociais 
mostram o cotidiano através das selfie's, o interesse dos jovens por esta ação é visto aqui enquanto potência pedagógica, passível de realizar um trabalho estético e emblemático, à medida que propõe a reflexão com estes próprios sujeitos produtores de imagens. Assim, ciente da dimensão do uso dos artefatos tecnológicos no dia a dia, a escola não fica externa a tal influência.

Apesar da diferença estar no chão da escola, ser constitutiva e intrínseca às práticas educativas (CANDAU, 2011), a instituição escolar trabalha com lógicas excludentes, normatizadoras e normalizadoras, opostas à base que a sustenta. Os processos de hibridização cultural são intensos e mobilizadores da construção de identidades abertas, em constituição permanente, o que supõe que as culturas não são puras, nem estáticas. A dificuldade de se lidar nas práticas educativas com as diversas manifestações da diferença, suscita no âmbito escolar o apagamento ou silenciamento das diversas vozes que constituem tal espaço. Assim, na perspectiva do multiculturalismo interativo, compreende-se que o presente projeto de mestrado trabalha com alguns pressupostos, tais como: diálogo entre diversos saberes e conhecimentos; reconhecimento dos processos de hibridização cultural e inter-relações entre os mais diversos sujeitos (CANDAU, 2011).

Deste modo, "ter presente a dimensão cultural é imprescindível para potenciar processos de aprendizagem mais significativos e produtivos para todos os alunos e alunas" (CANDAU, 2011, p. 242). Pensar a escola é estar ciente da existência e convivência de diferentes grupos sócio-culturais em um mesmo ambiente. Logo, por que não ter atividades pedagógicas que façam emergir essas diferenças, ao invés de silenciá-las? Não trabalhar o conflito é abafar a diferença, continuando com a visão comum de algo que deve ser ignorado ou visto enquanto um problema (CANDAU, 2011).

Enquanto professora, cabe a responsabilidade própria da função, de um olhar diferenciado sobre as múltiplas realidades que se apresentam dentro da escola. Pensando nisso e em consonância com a necessidade de se conhecer os educandos a fim de se ir ao encontro da educação libertadora e transgressora, é impossível conhecer os estudantes sem saber de seus locais, seus trajetos, suas histórias.

A produção de imagem é sempre a leitura da sociedade e ao mesmo tempo um ponto de vista, que se transforma em outros pontos imediatamente quando lida por terceiros. Ao retratar uma cena social, há ali um olhar que conduz e direciona a objetiva, narrando uma história. Neste sentido, seria possível mostrar as dinâmicas sociais através da fotografia? Através desta indagação inicial, diversas outras questões apresentam-se. No que ajudaria mostrar tais dinâmicas? Na perspectiva de sujeitos sociais, o que fazer com estas realidades 
conflitantes que nos deparamos cotidianamente? As fotografias revelam símbolos culturais, "podendo ser tratados assim como documentos etnográficos, precisando ser contextualizados socioculturalmente para serem utilizados como estudo acadêmico" (SCHERER, 1995, p. 72). Eis o surgimento da proposta de uma antropologia compartilhada, discutindo com os sujeitos o que para eles é fundamental de se inserir nessa narrativa. O que eles veem e permitem ver, o que é importante trabalhar, extrair da imagem as suas possibilidades narrativas, de construções, desconstruções e possíveis intervenções.

É essencial ressaltar que a fotografia traz historicidade e ideologias junto de seus clicks's, não sendo meramente evidências. São históricas em si mesmas (EDWARDS, 1996, p.15). Através destas narrativas fotográficas, é possível realizar um deslocamento temporal e espacial. Toda história é construída de fragmentos selecionados, é uma síntese para generalização, visto que o olhar recorta a cena geral que é capturada pela lente. Consciente de que a realidade é feita de múltiplas falas e pontos de vistas, e de que a fotografia é um resultado destes fragmentos, é necessário o cuidado para que não ocorra uma apropriação interpretativa da imagem em um discurso específico. A imagem enquadra essa situação social no espaço. Reduz ou amplia o contexto social nesse enquadramento, trabalha nessa percepção dupla do espaço que está sendo analisado ao qual o fabricante de imagens dá a esses sujeitos no seu enquadramento. Contém visões análogas de mundo. Assim, há de se ter claro que "a complexidade dos contextos de percepção da "realidade", enquanto manifestada na criação de imagens, cruza-se com a complexidade da natureza da fotografia em si, de várias formas." (EDWARDS, 1996, p.15)

Em suma, a linguagem escolhida foi a fotografia pois nos convida a considerar mais a sério o quanto o visual pode ser antropologicamente informado. A prática pode ser comprometida como uma forma de intervenção social (PINK, 2006) no sentido de poder ressignificar as relações verticalizadas da escola, à medida que protagoniza as narrativas dos educandos. Como apontado por Agier (2015), como na função do etnólogo, a fotografia vem como possibilidade de aproximar, de possibilitar um diálogo, de modo que permita a outros sujeitos ver o que nunca foi percebido ou até mesmo de desconstruir achismos.

\section{Metodologia}

A princípio a pesquisa havia sido pensada para estudantes do Ensino Fundamental II. Contudo, a pesquisa de campo está sendo realizada com estudantes do $2^{\circ}$ e $3^{\circ}$ ano do Ensino Médio, com idade entre 17 e 18 anos. Tal fator se deu pela facilidade de entrada na instituição, ao qual os diretores sugeriram que as oficinas fotográficas fossem realizadas com 
as turmas do Programa Emergencial de Ações Sociais. A escola situa-se em São João de Meriti, município da Região Metropolitana do estado do Rio de Janeiro.

Reforço que me apresento enquanto professora-pesquisadora e não enquanto fotógrafa, visto que não tenho formação na referida área. Logo, não possuo a presunção de trabalhar técnicas e/ou cobrar enquadramento mas, por enxergar na fotografia uma linguagem possível de retratar diferentes realidades e proporcionar reflexões/intervenções, eis a escolha da etnografia visual enquanto uma possibilidade de trabalho. Encontro-me aqui enquanto professora-pesquisadora que percebe na fotografia uma linguagem acessível, de modo que possa "contribuir para uma forma de divulgação do conhecimento que seja menos autoritária, mais interativa e talvez mais evidente no seu processo de reconstrução da realidade que se quer revelar". (NOVAES, 2009, p.44).

A fim de seguir na direção de uma ação que vise o direito à expressão, enquanto modo de divulgar as experiências e visões de mundo dos educandos, será utilizado o próprio celular do estudante. O uso de tecnologias DIY (Do It Yourself), portáteis e móveis, equipadas com recursos (áudio)visuais permitirá a materialização deste processo. Assim estruturar-se-ão novas dinâmicas e novos processos educacionais, centrados na percepção própria e autoconstrução de histórias. Um ato de resistência e de singularização promovido nas e pelas camadas populares das periferias.

Pedagogo e filósofo brasileiro, Freire utiliza-se das chamadas palavras-geradoras para alfabetizar jovens e adultos das classes populares. Criou um método de alfabetização que tomou a dimensão cultural e o diálogo enquanto bases - foi a primeira perspectiva intercultural, como afirma Candau (2011). À luz do educador brasileiro, as oficinas de fotografia também fazem uso das palavras-geradoras e do Círculo de Cultura enquanto metodologia. Deste modo, todo início de aula é feito em círculo e é através dos diálogos, com a contação das vivências e compartilhamentos, que se constrói o material da presente pesquisa. Diferentes linguagens como a literatura, música, imagens diversas, histórias de fotógrafas e fotógrafos são pontapés para iniciar a discussão dos distintos significados das palavras-geradoras como "vida", "alegria" e "tristeza". Fotografias surgem inspirando-se nestas palavras, trazendo narrativas das trajetórias destes estudantes, ao qual é neste momento de troca que ocorre a análise e discussão do processo que levou à produção imagética. A proposta permeia o conceito de existir como apresentado por Freire, onde “(...) existir, é um conceito dinâmico. Implica numa dialogação eterna do homem com o homem. Do homem com o mundo.” (FREIRE, 1964, p. 59) 


\section{Considerações parciais}

A angústia que me tira o sono de professora é a mesma que me tira o sono enquanto mestranda: como caminhar diferente? Diante de tantos questionamentos acerca das práticas escolares e do que seria meu objeto de estudo, percebi que as inquietações desaguavam em um mesmo rio: a práxis. Práxis esta que se faz com e pelo outro, sempre em conjunto, nunca de maneira solitária - como muitas falas no meio docente insistem em dizer para os que creem na utopia possível. Essa aflição tornou-se ação quando percebi que era no chão da escola que encontraria respostas, pois é só no fazer que as possibilidades se abrem. Uma ironia, tendo em vista que a princípio eu desejava fugir a todo custo da formalidade escolar. Demorei, mas percebi que o que tira meu sono é também o que me alimenta: os estudantes. Assim, a cada semana, a cada oficina ministrada, percebo muito do que é possível mudar na medida em que escuto cada voz explicando as fotografias, suas razões e motivações, suas queixas e suas vivências, procurando ler cada silêncio mesmo de quem não fez uma fotografia, mas continuava indo a toda aula. Deste modo, as considerações parciais devem ser lidas enquanto resultados esperados, tendo em vista a pesquisa e a análise de dados ainda em andamento.

Inspirada em Agier (2015), desejo com a presente pesquisa transformar os momentos da vida em riqueza, utilizando os registros fotográficos para capturar o cotidiano de modo a reconstruir um olhar e dar sentido ao que se olha. O que essas produções fotográficas suscitam em termos de narrativas? Quais histórias trazem? Metodologicamente vislumbra-se a possibilidade de situar a fotografia como espaço de cultura, inclusão e expressão, proporcionando uma quebra na aparente falta de diálogo que permeia a relação escolaestudante. Nesta instituição formal de ensino, comumente os educandos são expropriados de suas vivências, falas e atitudes. Por que não experenciar momentos de trocas, onde sua existência terá a oportunidade de se manifestar na linguagem visual?

Através da hipótese de que a imagem arde em contato com o seu real (Didi-Huberman, 2012, p. 208), que realidades são suscitadas a partir destas palavras-geradoras? Qual a chama que motiva o brilho no olhar para captar a imagem necessária? A ideia é provocar, através da fotografia, questões que vão além da esfera biologicamente vital, isto é, do ir e vir cotidiano. A transitividade da consciência (FREIRE, 1964) perpassa a inserção, integração e representação objetiva da realidade. Trabalhar com o conhecimento para a imagem pode proporcionar um desnudamento de diferentes esferas do âmbito individual e coletivo, além de provocar novas relações interpessoais e ressignificações entre os sujeitos que constituem a essência do âmbito escolar. 
Acredito que as relações perpassam a humanidade a qual todo sujeito deve fazer brotar, de modo crescente em cada contato, nutrindo o outro e alimentando-se das experiências alheias. Porque nós somos mais quando partilhamos e assim o desejo de poder contribuir para relações mais humanas, empáticas e sensíveis cresce quando penso que esta pesquisa pode caminhar neste sentido. Que as falas dos educandos, sejam estas na linguagem fotográfica ou nas palavras transcritas, possibilitem um descortinar do senso comum, a saída da bolha, emergindo cada vez mais a partilha do sensível.

A construção do portfólio de cada aluno é também, porque não, a construção de um novo tipo de escola que percebe no outro os seus alicerces fundamentais para a consolidação de um projeto que vise o coletivo enquanto inseparável.

Ironicamente, a justificativa do tempo também atravessou o presente projeto, minha prática, meus objetivos. Desde o início a falta dele impediu um maior aprofundamento. A oficina de cerca de 60 minutos tinha que ser o suficiente para que pudéssemos analisar as fotografias, falar de nós mesmos, mergulhar na imensidão que era cada narrativa emergindo naqueles Círculos de Confiança. Se foi possível? Claro que não. Faltou, e faltou muito. Conhecer o outro demanda tempo - e este senhor é tudo que menos temos nesta sociedade pós-moderna. Mas o entendimento que sempre estaremos no limite do possível é o que deve nos motivar para ir ao encontro do nosso máximo, pois a consciência de que o tempo presente é pouco nos impulsiona a fazer do agora o melhor de nossa existência. O desejo de não ser mais uma dissertação de fotografia me motiva a encontrar algo diferente nessa pesquisa - e ainda estou nesse caminho. Quero escrever sobre algo que faça alguma diferença, pois não é apenas a conquista de mais um título, é a intenção de fazer brotar novos paradigmas diante de tantas ações comuns. A consciência dessa limitação também foi importante para (lembrar) que a educação não é a salvadora de todos os males - mas é sim espaço de luta e de encontros.

\section{Referências}

ADORNO, Theodor W. Educação — para que? Debate na Rádio de Hessen; transmitido em 26 de setembro de 1966; publicado em NeueSammlung, janeiro/fevereiro de 1967.

AGIER, Michel. Encontros etnográficos: interação, contexto, comparação. 1. Edição, São Paulo: Editora Unesp; Alagoas: Edufal, 2015

CANDAU, Vera. Diferenças culturais, cotidiano escolar e práticas pedagógicas. Currículo sem Fronteiras, v.11, n.2, pp.240-255, Jul/Dez 2011. 
DIDI-HUBERMAN, Georges. Quando as imagens tocam o real' Didi-Huberman. Pós: Belo Horizonte, v. 2, n. 4, p. 204 - 219, nov. 2012.

EDWARDS, Elizabeth. Antropologia e Fotografia. Cadernos de Antropologia e Imagem 2: 11-28, 1996.

FREIRE, Paulo. Educação como prática da liberdade. Rio de Janeiro: Paz e Terra, 1967.

FREIRE, Paulo. Pedagogia da Autonomia: saberes necessários à prática educativa. Rio de Janeiro: Paz e Terra, 1997.

HALL, Stuart. A identidade cultural na pós-modernidade. 11a ed. Rio de Janeiro: DP\&A; 2006.

HOOKS, Bell. "Introdução" (p.9-24); "Pedagogia Engajada” (p.25-36). In: Ensinando a transgredir: a educação como prática da liberdade. Tradução de Marcelo Brandão de Cipola. São Paulo: Editora WMF Martins Fontes, 2013.

NOVAES, Sylvia Caiuby. Imagem e Ciências Sociais: trajetória de uma relação difícil. In: BARBOSA, Andréa; CUNHA, Edgar da; HIKIJI, Rose (Org.). Imagem-Conhecimento: antropologia, cinema e outros diálogos. Campinas: Papirus, 2009. P. 35-60.

PINK, Sara. Visual engagement as social intervention: applied visual anthropology. In PINKS S. The future of visual anthropology. Engaging the senses. London: Routledge, 2006, p. 81102.

SCHERER, Joanna. Documento fotográfico: fotografias como dado primário na pesquisa antropológica. Cadernos de Antropologia e Imagem 3: 69-83, 1995. 